\title{
IL-10 expression defines an immunosuppressive dendritic cell population induced by antitumor therapeutic vaccination
}

\author{
Diana Llopiz ${ }^{1,2}$, Marta Ruiz ${ }^{1,2}$, Stefany Infante ${ }^{1}$, Lorea Villanueva ${ }^{1}$, Leyre Silva $^{1,2}$, \\ Sandra Hervas-Stubbs ${ }^{1,2}$, Diego Alignani ${ }^{2,3}$, Elizabeth Guruceaga ${ }^{2,4}$, Juan J. \\ Lasarte $^{1,2}$, Pablo Sarobe ${ }^{1,2}$ \\ ${ }^{1}$ Program of Immunology and Immunotherapy, Center for Applied Medical Research (CIMA), University of Navarra, Pamplona, \\ Spain \\ ${ }^{2}$ IdiSNA, Instituto de Investigación Sanitaria de Navarra, Pamplona, Spain \\ ${ }^{3}$ Cytometry Unit, Center for Applied Medical Research (CIMA), University of Navarra, Pamplona, Spain \\ ${ }^{4}$ Bioinformatics Unit, Center for Applied Medical Research (CIMA), University of Navarra, Pamplona, Spain
}

Correspondence to: Pablo Sarobe, email: psarobe@unav.es

Keywords: dendritic cells, therapeutic vaccination, $I L-10, P D-L 1$, immunoregulation

Received: September 14, $2016 \quad$ Accepted: November 22, $2016 \quad$ Published: December 01,2016

\section{ABSTRACT}

Vaccination induces immunostimulatory signals that are often accompanied by regulatory mechanisms such as IL-10, which control T-cell activation and inhibit vaccine-dependent antitumor therapeutic effect. Here we characterized IL10-producing cells in different tumor models treated with therapeutic vaccines. Although several cell subsets produced IL-10 irrespective of treatment, an early vaccine-dependent induction of IL-10 was detected in dendritic cells (DC). IL-10 production defined a DC population characterized by a poorly mature phenotype, lower expression of T-cell stimulating molecules and upregulation of PD-L1. These IL-10+ DC showed impaired in vitro T-cell stimulatory capacity, which was rescued by incubation with IL-10R and PD-L1-inhibiting antibodies. In vivo IL-10 blockade during vaccination decreased the proportion of $\mathrm{IL}^{-10^{+}} \mathrm{DC}$ and improved their maturation, without modifying PD-L1 expression. Similarly, PD-L1 blockade did not affect IL-10 expression. Interestingly, vaccination combined with simultaneous blockade of IL-10 and PD-L1 induced stronger immune responses, resulting in a higher therapeutic efficacy in tumor-bearing mice. These results show that vaccine-induced immunoregulatory IL-10+ DC impair priming of antitumor immunity, suggesting that therapeutic vaccination protocols may benefit from combined targeting of inhibitory molecules expressed by this DC subset.

\section{INTRODUCTION}

The tumor microenvironment is characterized by the presence of immunosuppressive molecules which induce inhibitory effects on antitumor immunity [1]. This microenvironment precludes correct activation of antigen-presenting cells (APC) responsible for priming T-cell responses [2] and the effector phase of tumorspecific lymphocytes [3, 4]. Characterization of these immunosuppressive molecules has allowed the design of new therapies aimed at blocking their inhibitory functions, leading to activation of antitumor immunity and efficient clinical effects [5, 6]. Moreover, besides expression induced as a consequence of tumor growth, some therapies with an immunological component may also induce inhibitory elements as a negative feed-back mechanism [7]. Among them, vaccination induces not only T-cell-activating molecules, but also immunomodulatory mechanisms which regulate immune response activation [8-12].

IL-10 is a cytokine traditionally considered immunosuppressive due to its anti-inflammatory properties, mainly acting on APC by inhibiting expression of inflammatory cytokines and surface molecules associated with T-cell activation [13]. Different APC, including dendritic cells (DC), monocytes, macrophages and B-cells, as well as effector and regulatory $\mathrm{T}$ lymphocytes, produce IL- 10 [14]. However, besides inhibitory effects on APC with the concomitant down-regulation of T-cell activation, 
IL-10 may also have a stimulatory role by enhancing effector functions on activated CD8 T-cells and by activating NK cells through inhibition of MHC molecules [15-17]. In cancer patients, elevated IL-10 levels are associated with a poorer prognostic [18-20], suggesting that its inhibition would have a beneficial effect [21]. We and others have shown that inhibition of IL-10 during vaccination enhances the magnitude of T-cell responses $[22,23]$. Furthermore, during therapeutic vaccination of mice bearing IL-10-expressing tumors, we have recently reported the relevance of vaccine-induced IL-10, as opposed to that derived from the tumor, demonstrating its importance in the control of T-cell activation and in the therapeutic efficacy of vaccines [23]. Therefore, characterization of events associated with IL-10 production during vaccination may allow the design of better antitumor therapies. In the present work we identify cell populations producing IL-10 during therapeutic vaccination, analyzing their properties and potential association with other immunosuppressive pathways. We have observed that IL-10 is induced in DC with a less mature phenotype and decreased T-cell activation capacity. Moreover, they express additional immunomodulatory molecules like PD-L1, which contribute to their poor immunogenicity. Characterization of these molecules in DC sets the rationale to design new strategies combining therapeutic vaccines with blockade of relevant associated immunosuppressive molecules.

\section{RESULTS}

\section{DC consistently produce IL-10 in an Imiquimod- dependent manner}

To characterize relevant IL-10-producing cells induced during therapeutic vaccination, we used IL-10 reporter Vert-X mice [24]. Since IL-10 plays an inhibitory role even during vaccination of naive tumor-free mice [23], we started identifying IL- $10^{+}$cells in this setting. Mice were vaccinated with OVA+Imiquimod and compared to controls groups of untreated mice (UT) or mice vaccinated with OVA+poly(I:C), a vaccine in which IL-10 blockade did not provide any antitumor benefit [23]. In Imiquimodvaccinated mice, contrary to those in UT and poly(I:C) groups, a higher proportion of total splenic IL- $10^{+}$cells was detected two days after treatment (Figure 1A). Most populations specifically produced IL-10 after Imiquimod vaccination (Figure 1A and Supplementary Figure S1). However, DC clearly surpassed values observed for other cells. Regarding lymph nodes, DC and monocytes showed the highest proportions of Imiquimod-specific IL- $10^{+}$cells (Figure 1B). Vaccination of mice bearing B16-OVA tumors showed that Imiquimod induced again a general increase in the total splenic population, corresponding to higher values in all subsets (Figure 1C), a result corroborated when analyzing tumor-draining lymph nodes (Figure 1D). As in tumor-free mice, DC and monocytes showed the highest proportion of IL- $10^{+}$cells. High values were also observed in Tregs and NK cells, although this was not induced only by Imiquimod, since poly(I:C) also induced IL-10. Analysis of IL- $10^{+}$cells inside the tumor showed that most populations produced IL-10. However, IL-10 production was not Imiquimod-specific, since clear IL-10 production was detected in poly(I:C)-treated mice and even in some subsets in UT mice (as observed for Tregs), as we previously reported in tumor homogenates [23]. Of note, DC did not produce IL-10 in UT mice, and in vaccinated mice, probably due to adjuvant-induced migration, DC could not be detected in sufficient numbers to be analyzed (Supplementary Figure S2).

Equivalent vaccination experiments in mice bearing TC-1 and E.G7-OVA tumors showed that although in most splenic cell populations the proportion of IL-10-producing cells increased after vaccination with Imiquimod, DC was the cell subset with the highest proportion of IL- $10^{+}$cells (Figures 1E-1F). These results show that several subsets, but mainly DC, consistently upregulate IL-10 production after vaccination in an Imiquimod-dependent manner.

\section{IL-10 with inhibitory effects on T-cell activation is induced at early time points after vaccination}

To support that GFP expression observed in Vert-X mice indeed corresponded with IL-10, RT-PCR experiments measuring $I l 10$ mRNA were carried out in C57BL/6 mice vaccinated with OVA+Imiquimod. To avoid missing IL-10 production at time points other than day 2, time-course experiments were carried out from day 1 to 7 . We analyzed $I l 10$ mRNA in purified splenic $\mathrm{CD} 11 \mathrm{c}^{+} \mathrm{DC}$ and $\mathrm{CD} 4^{+} \mathrm{T}$-cells, representative of innate [25] and adaptive [22] cell populations producing IL-10. In DC IL-10 peaked at day 2, returning to basal levels at day 7 , whereas in $\mathrm{CD} 4^{+} \mathrm{T}$-cells, following a first peak at day 1 which decreased by day 4, a second, albeit weaker increase, was observed at day 7 (Figure 2A).

The second IL-10 peak observed at day 7 in $\mathrm{CD}^{+}$cells prompted us to study IL-10 production by other cell populations at this time point, using tumorfree mice, since equivalent results had been observed in lymphoid organs from tumor-free and tumor-bearing mice. Splenic CD4 Tregs maintained high Imiquimodindependent IL-10 production, whereas in remaining subsets a marginal Imiquimod-specific induction was observed only in effector CD4 and in CD8 and NK cells (Figure 2B), according to PCR results of CD4 cells shown in Figure 2A. Indeed, additional analyses of intracellular IL-10 using splenic cells from vaccinated C57BL/6 mice confirmed that effector CD4 and to a lesser extent CD8 T-cells, but not Tregs, specifically upregulated IL-10 in the Imiquimod group at day 7 (Figure 2C).

Since IL-10 blockade at day 0 enhanced T-cell responses [23], and two IL-10 peaks (an early peak mainly related to APC and a second peak related to T-cells) were 
detected, we studied the functional relevance of the second peak by blocking IL-10 at day 4 after vaccination. Blockade at this time-point did not provide any beneficial effect, indeed, poorer responses were obtained (Figure 2D), suggesting that the enhancement of immune responses observed after IL-10 blockade at day 0 is mainly due to inhibition of IL-10 produced at early time-points after immunization, during the priming phase.

\section{IL-10-producing DC have a different phenotypic and immunogenic profile and limit antitumor CD8 T-cell response activation}

Due to the important proportion of IL- $10^{+}$APC induced by OVA+Imiquimod and considering the role that these cells play in T-cell priming (mainly for DC),
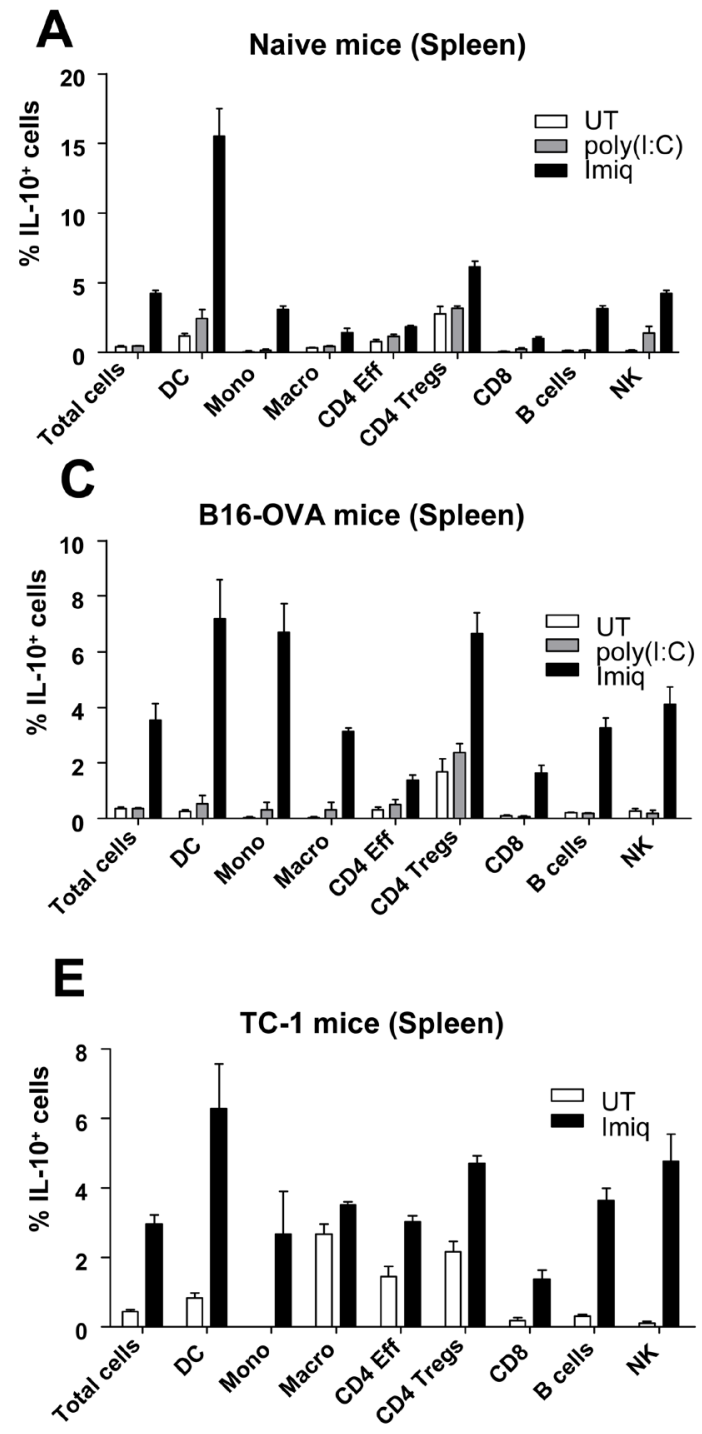

phenotypic analyses comparing IL- $10^{+}$and IL-10- cells were carried out after vaccination of naive and B16OVA tumor-bearing mice. IL- $10^{+}$DC had a less mature phenotype than their IL-10 $0^{-}$counterparts, displaying a significantly lower expression of markers CD54, CD80 and CD86 associated to cell adhesion and T-cell costimulation (Figure 3A). However, in remaining APC populations, no differences were observed, except for higher CD80 values on IL-10 ${ }^{+}$B-cells (Supplementary Figure S3). This immature phenotype of $\mathrm{IL}_{-} 10^{+} \mathrm{DC}$ was also observed in mice treated with other IL-10inducing vaccines. Indeed, EDA-OVA+MAC, a multiple adjuvant combination [26] whose antitumor effects also increased after IL-10 blockade [23] or OVA+LPS, [27] also induced IL-10 $0^{+}$DC with a similar phenotype (Supplementary Figure S4).
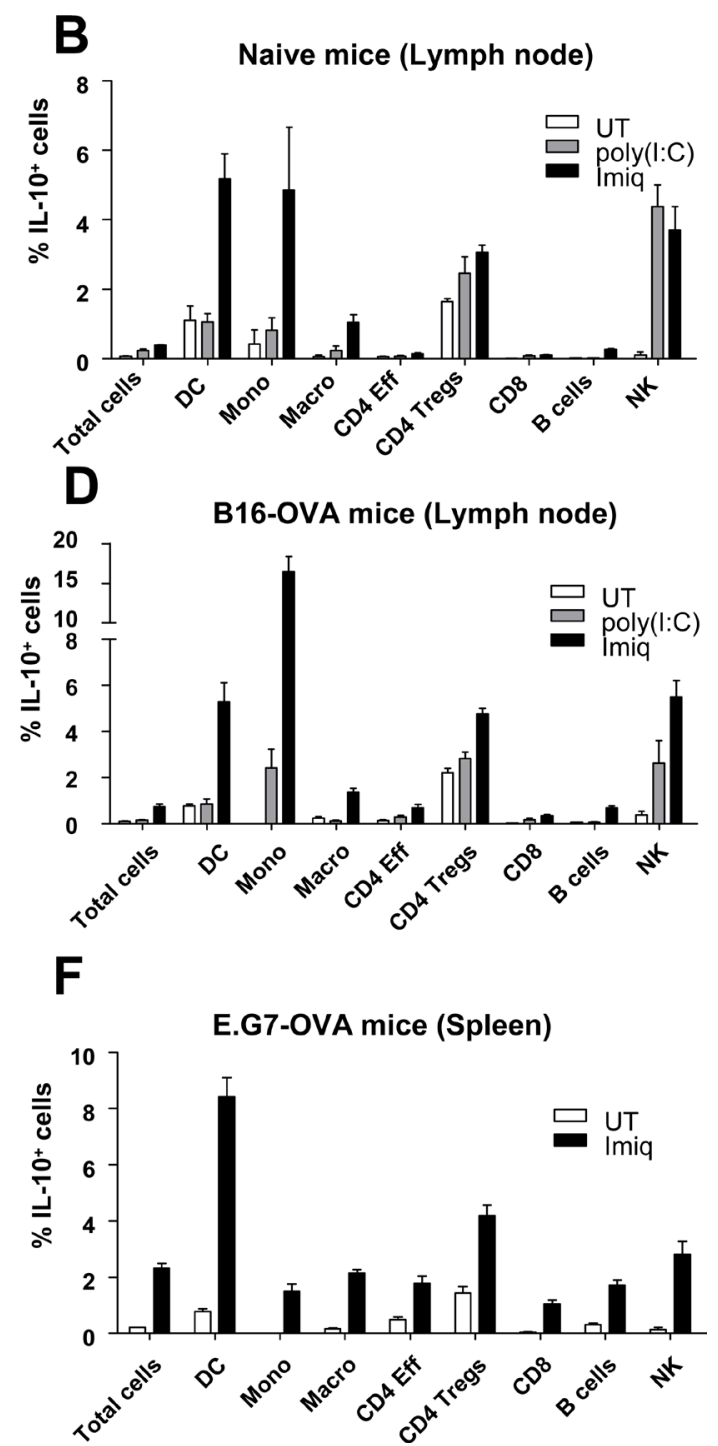

Figure 1: Identification of cell subsets producing IL-10 after therapeutic vaccination. Naive Vert-X mice (A-B), mice bearing $5 \mathrm{~mm}$ B16-OVA $(\mathbf{C}-\mathbf{D})$, TC-1 (E) or E.G7-OVA tumors $(\mathbf{F})(n=8-11$ /group) were vaccinated with antigen (OVA in A-D and F or EDA-HPV-E7 in E) plus Imiquimod, antigen plus poly(I:C) or left untreated (UT). Two days later spleens or lymph nodes were obtained and the percentage of IL-10-producing cells was determined by flow cytometry in total cells and in the different subsets. Results correspond to the sum of $2-3$ independent experiments. 
Additional features of IL- $10^{+} \mathrm{DC}$ were studied in purified splenic DC from Imiquimod-vaccinated mice. Regarding stimulatory cytokines, qPCR experiments showed that IL- $10^{+}$DC had lower levels of transcripts for Tnf and Il12b (encoding TNF- $\alpha$ and IL-12 p40, respectively). Interestingly, in the case of regulatory molecules, although no differences were observed in the expression of the tryptophan-catabolizing enzyme Ido1 (Figure 3B), higher surface PD-L1 expression was found in $\mathrm{IL}-10^{+} \mathrm{DC}$ after immunization of naive mice or mice with different tumors (Figure 3C). These differences between IL- $10^{+}$and IL-10- DC in activating and inhibitory molecules led us to carry out transcriptomic studies. Differentially expressed genes were grouped in Gene Ontology terms and most over-represented terms corresponded to regulation of immune system process $\left(p=2.13 \times 10^{-12}\right)$, leukocyte activation $\left(p=7.19 \times 10^{-9}\right)$, immune response $\left(p=1.08 \times 10^{-8}\right)$ and cell activation $\left(p=9.97 \times 10^{-8}\right)$. Analyses of individual genes showed
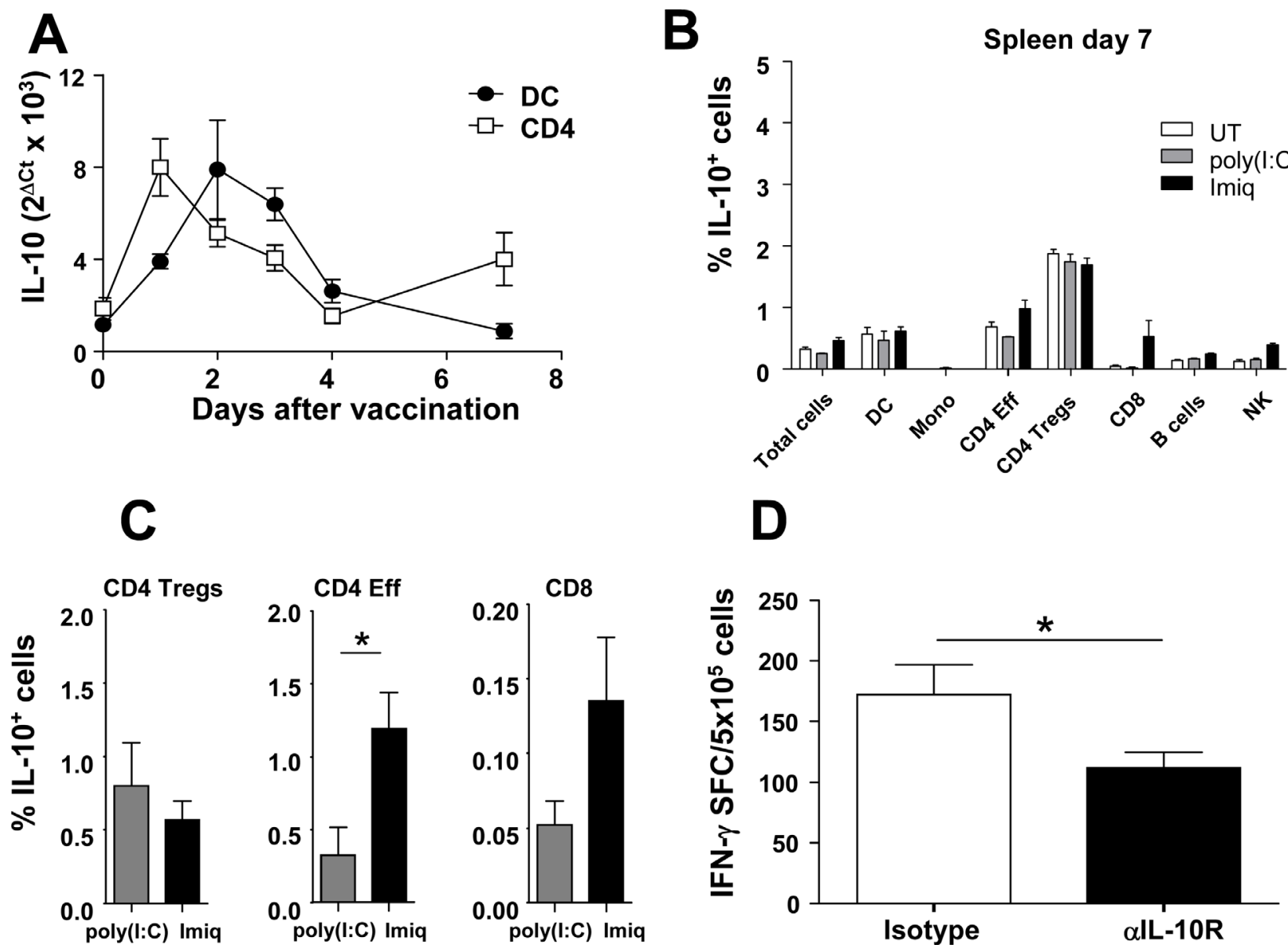

Figure 2: IL-10 with inhibitory effects on T-cell activation is induced at early time points after vaccination. (A) C57BL/6 mice ( $n=5 /$ time-point) were vaccinated with OVA+Imiquimod and IL-10 mRNA was quantified by qPCR at different time-points in purified DC and CD4 cells. (B) Vert-X mice ( $n=8$ /group) were vaccinated with OVA+Imiquimod, OVA+poly(I:C) or left untreated (UT) and one week later the percentage of splenic IL-10-producing cells was determined by flow cytometry. (C) C57BL/6 mice $(n=4)$ were vaccinated with OVA+Imiquimod or OVA+poly(I:C) and one week later splenocytes were stimulated with PMA/Ionomycin and intracellular IL-10 was determined by flow cytometry. (D) C57BL/6 mice $(n=4)$ were vaccinated with OVA+Imiquimod with or without blockade of IL-10 at day four after vaccination. At day 7, OVA-specific responses were determined by ELISPOT. Results are representative of 2 independent experiments. 
their immunosuppressive role (Figure 4B). To test in vivo the functional relevance of DC-derived IL-10, vaccination experiments were carried out in IL- $10^{\mathrm{f} / \mathrm{fl}} \times \mathrm{CD} 11 \mathrm{c}-\mathrm{Cre}^{+}$ mice, selectively lacking IL-10 in DC, or in IL-10 $0^{\mathrm{f} / \mathrm{fl}} \mathrm{x}$ LysM-Cre ${ }^{+}$mice, lacking IL-10 mainly in myeloid cells (monocytes/macrophages/granulocytes). Immunization with OVA+Imiquimod induced stronger T-cell responses in mice lacking IL-10 in DC than in their littermates with IL-10-proficient DC. However, no statistically significant differences were observed in mice lacking IL-10 in myeloid cells (Figure 4C). More importantly, similar to the results obtained when combining therapeutic vaccination
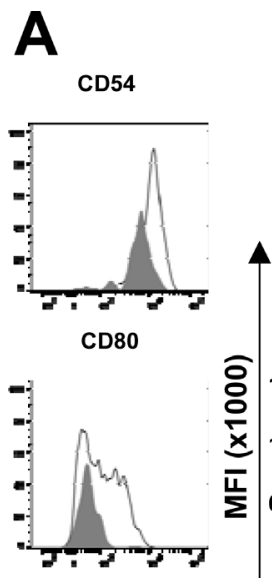

Naive mice B16-OVA mice
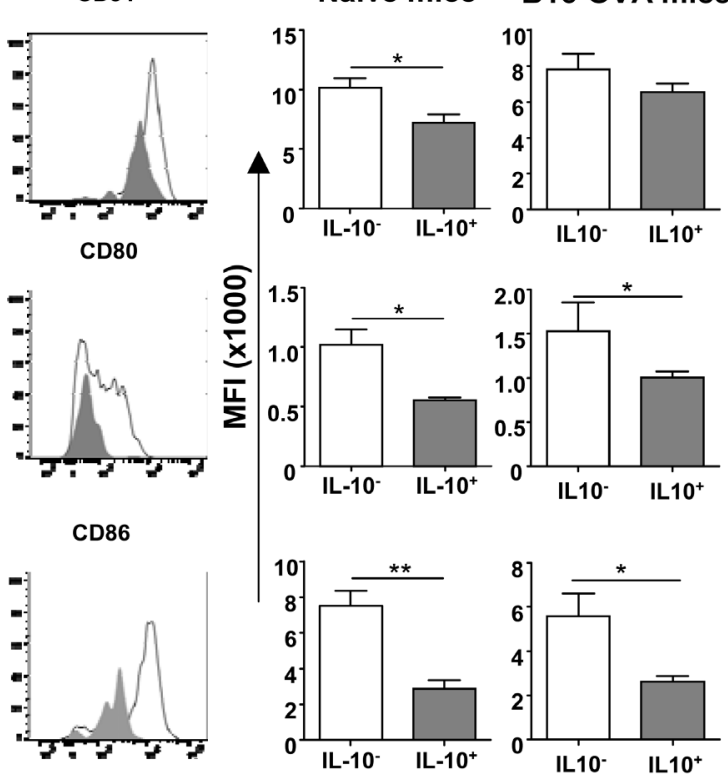

D
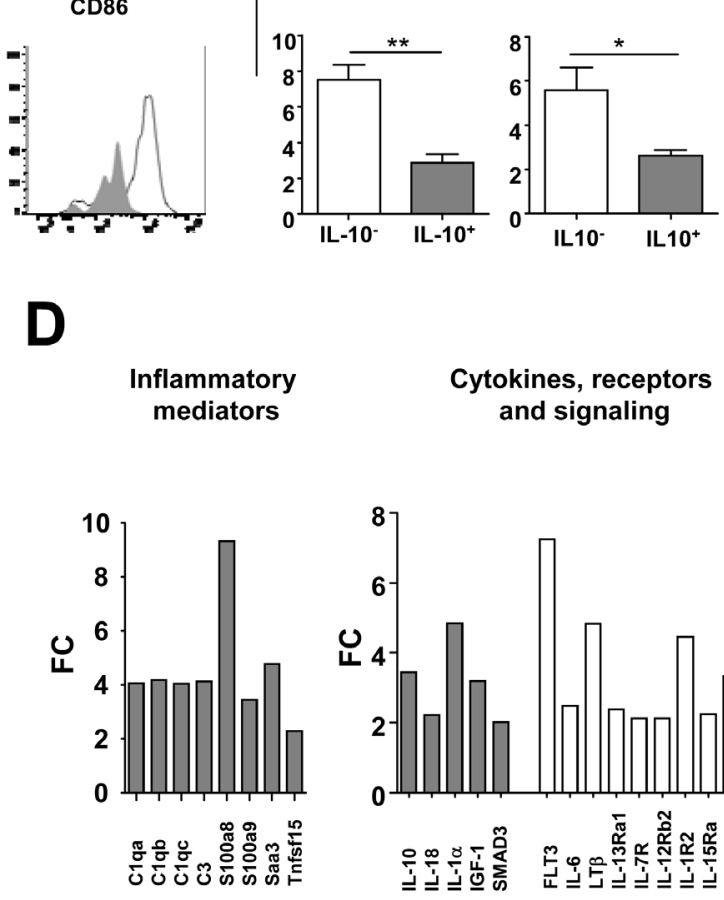

ytokines, receptors
and signaling

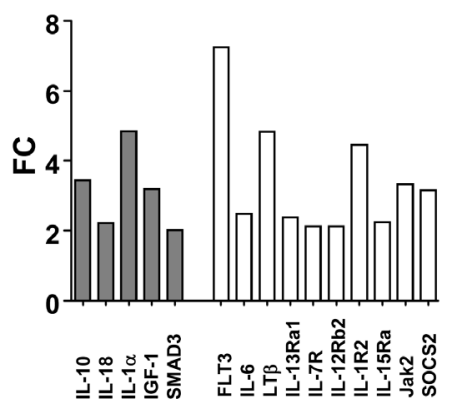

plus systemic IL- 10 blockade [23], treatment of E.G7-OVA tumor-bearing mice with the OVA+Imiquimod vaccine had a stronger antitumor effect in mice lacking IL-10 in DC than in those having competent DC (Figure 4D). Indeed, whereas only $16 \%$ of mice with IL- $10^{+} \mathrm{DC}$ rejected their tumor, $67.5 \%$ of tumors were rejected in mice lacking IL-10 in DC. Overall, these results stress the importance of IL- $10^{+}$DC which, besides producing this immunosuppressive factor, are in a less-immunogenic condition, both at the phenotypical and functional level, leading thus to poorer CD8 T-cell priming during vaccination and restraining treatment efficacy.
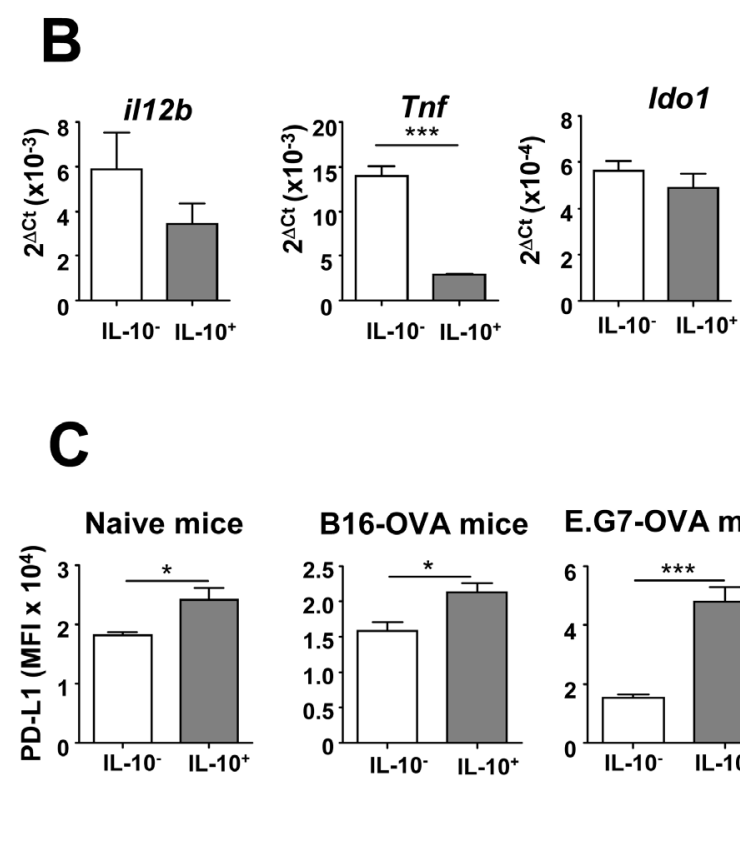

B16-OVA mice
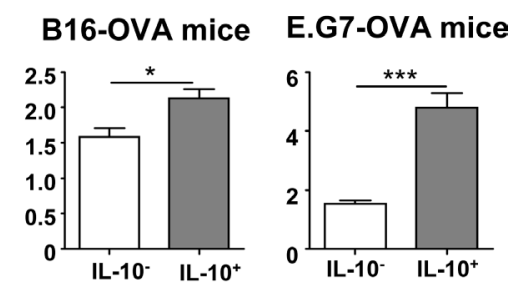

Chemokines, receptors and adhesion molecules
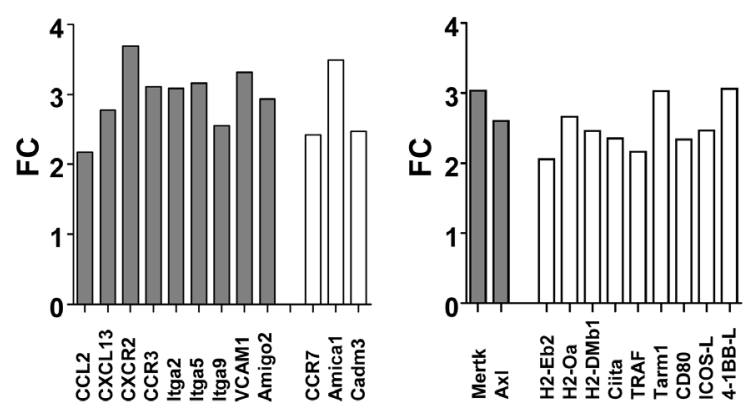

Figure 3: IL-10-producing DC have a different phenotypic and immunogenic profile. (A) Maturation associated markers were determined in IL-10- and IL- $10^{+}$DC from Vert-X mice $(n=4)$ with or without B16-OVA tumors two days after vaccination with OVA+Imiquimod. Left column corresponds to representative results of CD54, CD80 and CD86 molecules in DC from a vaccinated naive mouse, whereas middle and right columns show data corresponding to same markers in grouped naive and B16-OVA-vaccinated animals. (B) mRNA expression of several genes was analyzed by qPCR in purified IL-10- and IL-10+ DC from Vert-X mice $(n=8)$ vaccinated as in A. (C) PD-L1 expression was measured by flow cytometry in DC from naive and B16-OVA and E.G7-OVA tumor-bearing mice $(n=4)$. Results are representative of 2-3 independent experiments. (D) Gene expression was analyzed in DC subsets. Results are shown as foldchange (FC), with upregulation in IL-10 ${ }^{+}$DC (gray bars) or in IL-10- DC (white bars). 
In vivo IL-10 blockade rescues mature phenotype of DC

We described that IL-10 blockade during therapeutic vaccination increased T-cell responses, associated with a more mature DC phenotype and enhanced functions, such as IL-12 production [23]. Thus, to dissect this rescuing effect of IL-10 blockade, IL-10-producing cells were analyzed in Vert-X mice vaccinated with OVA+Imiquimod, subjected or not to IL-10 blockade. A trend leading to a lower proportion of IL- $10^{+}$cells was observed in whole splenic cells after IL10 blockade, which was statistically evident when specifically examining DC and B-cells. However, no differences were found in monocytes or macrophages (Figure 5A). Next, the effect of IL-10 blockade on DC phenotype was studied, according to their ability to produce IL-10. IL-10 blockade did not have any effect on IL-10- DC phenotype (data not shown). Interestingly, increased expression levels of costimulatory molecules were found in IL- $10^{+} \mathrm{DC}$ from mice treated with blocking antibodies (Figure 5B). These results indicate that both mechanisms, lower proportion of IL-10 DC and increased maturation, contribute to promote an overall higher number of mature DC after IL-10 blockade.
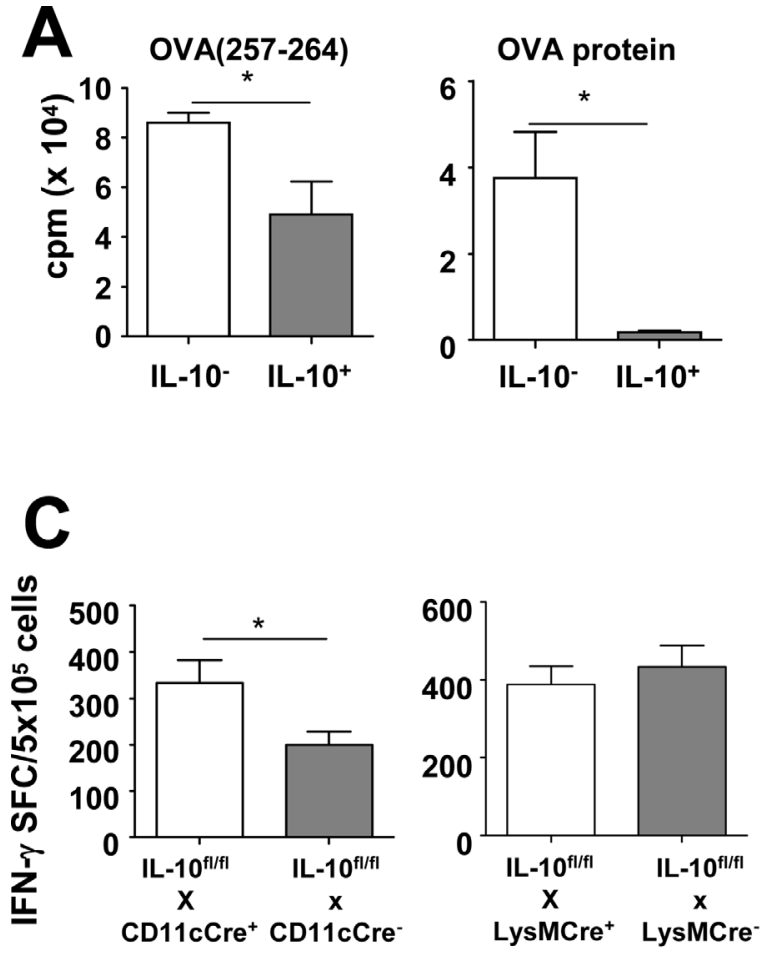

Imiquimod-based vaccination induces DC with dual IL-10/PD-L1 expression whose simultaneous blockade increases antitumor efficacy of therapeutic vaccines

Despite their less mature phenotype, IL- $10^{+} \mathrm{DC}$ displayed higher levels of PD-L1 (Figure 3C), a molecule associated with TLR-activated DC $[9,28-30]$ which is involved in tumor immunosuppression [31]. This PDL1 up-regulation was also observed in other IL- $10^{+} \mathrm{APC}$ (Supplementary Figure S5). We were thus interested in studying the association between IL-10 production and PD-L1 expression in different vaccination models. Examining whole splenocytes in B16-OVA-tumor-bearing mice, both poly(I:C)- and Imiquimod-based vaccines enhanced the proportion of PD-L1 expressing cells. However, Imiquimod, besides inducing IL-10, led to the highest percentages of PD-L1+ cells, a result also observed after vaccination of naive tumor-free mice (Supplementary Figure S6). When specifically considering DC, although most cells $(>95 \%)$ were PD-L1 ${ }^{+}$irrespective of the vaccine (data not shown), clear differences were observed when analyzing the intensity of PD-L1 expression. While
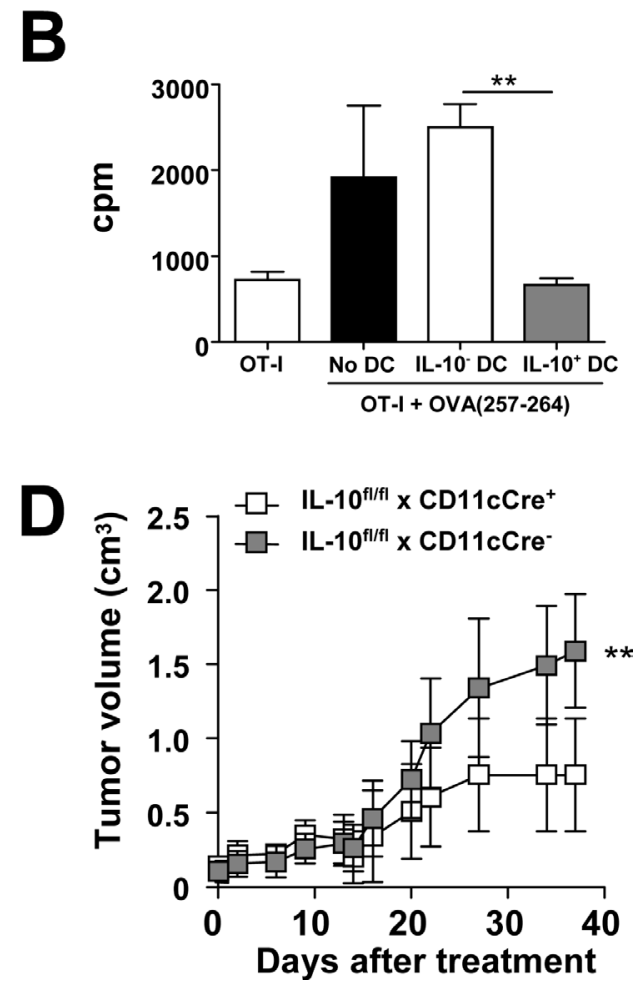

Figure 4: IL-10-producing DC have a poorer T-cell stimulatory capacity and limit the efficacy of anti-tumor therapeutic vaccination. (A) Purified IL-10 $0^{-}$and IL-10 $0^{+}$DC from Vert-X mice $(n=8-10)$ were pulsed with peptide OVA(257-264) or OVA protein and used to stimulate OT-I CD8 T-cells. T-cell proliferation was determined three days later. (B) Total OT-I splenocytes (OT-I Spl) were pulsed or not with peptide OVA(257-264) and after washing the peptide, some wells additionally received IL-10 ${ }^{-}$or IL-10 ${ }^{+}$DC and T cell

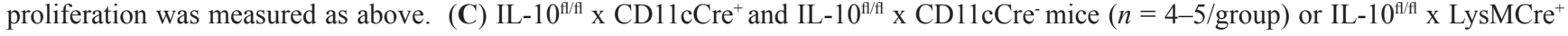
and IL-10 $0^{\mathrm{f} / \mathrm{f}} \mathrm{x}$ LysMCre mice ( $n=6 /$ group) were immunized with OVA+Imiquimod and one week later OVA-specific responses were determined by ELISPOT. Results are representative of 2-3 independent experiments. (D) $\mathrm{IL}-10^{\mathrm{f} / \mathrm{f}} \times \mathrm{CD} 11 \mathrm{cCre}{ }^{+}$and IL-10 $0^{\mathrm{f} / \mathrm{f}} \times \mathrm{CD} 11 \mathrm{cCre}$ mice ( $n=6-8$ /group) bearing $5 \mathrm{~mm}$ E.G7-OVA tumors were treated with three weekly vaccination cycles with OVA + Imiquimod and tumor volume was monitored. 
the poly(I:C)-based vaccine induced some increase regarding the UT group, Imiquimod-vaccinated mice expressed the highest PD-L1 levels, after vaccination of both tumor-bearing and naive mice (Figure 6A).

Enhanced PD-L1 levels on IL- $10^{+}$cells and data concerning interactions in the expression of these molecules [32-34] prompted us to analyze a potential association in their mutual expression. Thus, Vert-X mice were vaccinated with OVA+Imiquimod, with or without blockade of these molecules. IL-10 blockade did not modify PD-L1 expression, neither in IL- $10^{+}$nor in IL-10 $0^{-}$cells. This was observed when studying the whole splenic cell populations (Supplementary Figure S7A) and separately in DC (Figure 6B), B-cells, monocytes and macrophages (data not shown). Similarly, PD-L1 blockade did not modify the proportion of vaccineinduced IL- $10^{+}$cells (Figure 6C and Supplementary Figure S7B). To test the functional relevance of these immunosuppressive factors in IL- $10^{+} \mathrm{DC}$, we repeated in vitro antigen presentation assays combined with blocking antibodies. While PD-L1 blockade only induced a minimal increase in T-cell stimulation by IL-10- DC, both IL-10R and PD-L1 blockade clearly led to enhanced T-cell responses induced by IL-10 $0^{+}$DC (Figure 6D), suggesting that these immunosuppressive factors play important and independent roles as inhibitory molecules in IL- $10^{+}$DC in the vaccination setting. Although PD-1 expression was not detected in CD8 T cells in lymphoid organs of naive mice one week after vaccination (data not shown) presumably due to the low frequency of Ag-specific cells induced by the vaccine, PD-1 was observed in tumor bearing mice, whose OVA(257-264) Tetramer $^{+}$frequencies ranged between 5 and $8 \%$. Indeed, $20 \%$ of these Tetramer $^{+}$cells expressed PD-1 in tumor-draining lymph nodes whereas these values increased to $80 \%$ in tumor infiltrating $\mathrm{T}$ lymphocytes (Supplementary Figure S8), supporting that in vivo, similarly to IL-10 blockade, inhibition of PD-1/ PD-L1 axis would enhance vaccine-induced antitumor T cell responses. Accordingly, the rescuing effect observed after in vitro blockade was translated in vivo in vaccination experiments with dual blockade. Both IL-10R and PDL1 blocking antibodies enhanced vaccine-induced T-cell responses, which were clearly increased after combined administration (Figure 6E).

Since the combination of the vaccine with the simultaneous blockade of IL-10R and PD-L1 gave the best results in immunization experiments, we tested the antitumor therapeutic relevance of this strategy in mice bearing B16-OVA tumors. We chose anti-PD-1 antibodies to inhibit the PD-1/PD-L1 pathway, similarly to initially approved therapies against this axis. Although individual therapies based on vaccination or inhibitory antibodies had some effect on tumor growth, combination therapy potently inhibited tumor growth (Figure 6F).
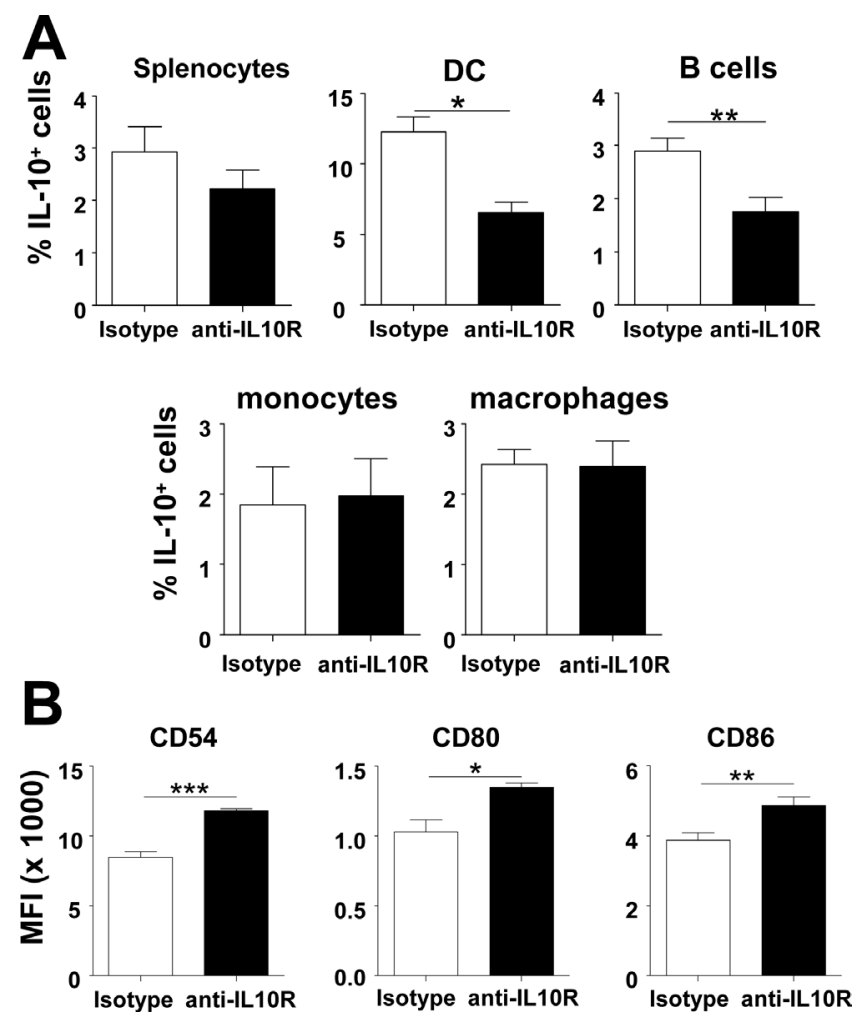

Figure 5: In vivo IL-10 blockade rescues mature phenotype of DC. (A) Vert-X mice $(n=4 /$ group $)$ were vaccinated with OVA+Imiquimod with or without IL-10 blockade and 2 days later the proportion of total splenic cells and DC, B-cells, monocytes and macrophages producing IL-10 was determined by flow cytometry. (B) Phenotype of IL-10 ${ }^{+}$DC from vaccinated mice was also analyzed in these groups. Results are representative of 2-3 independent experiments. 

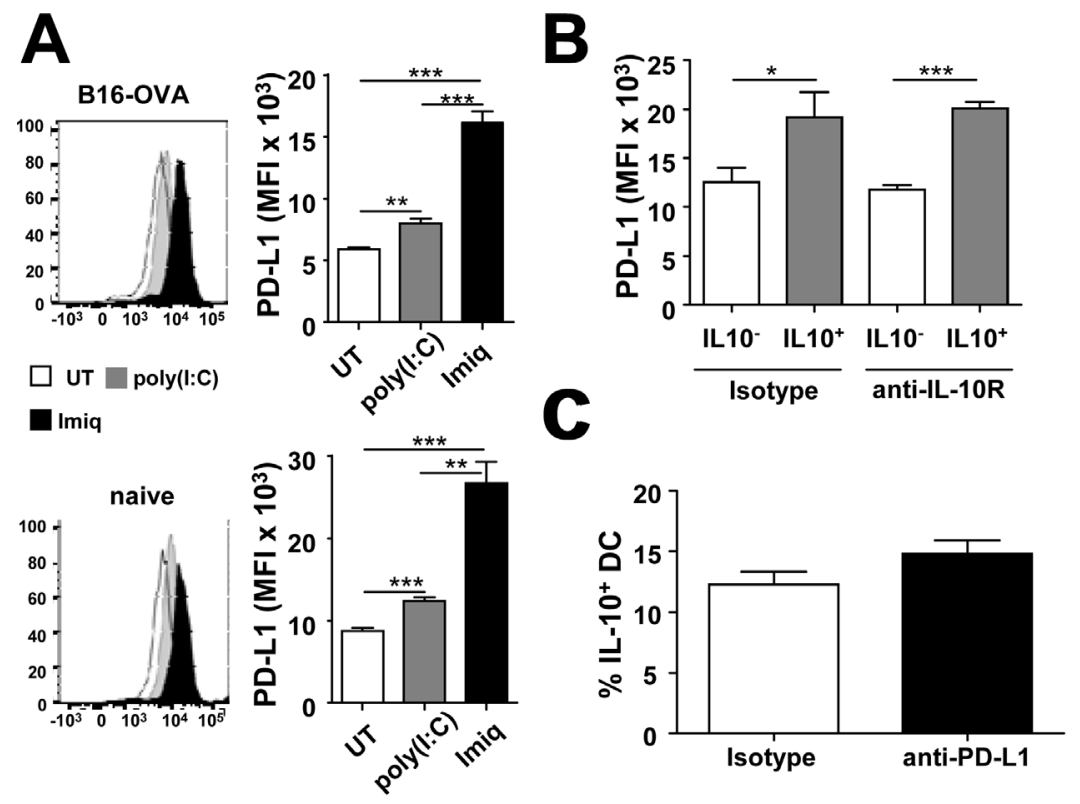

D
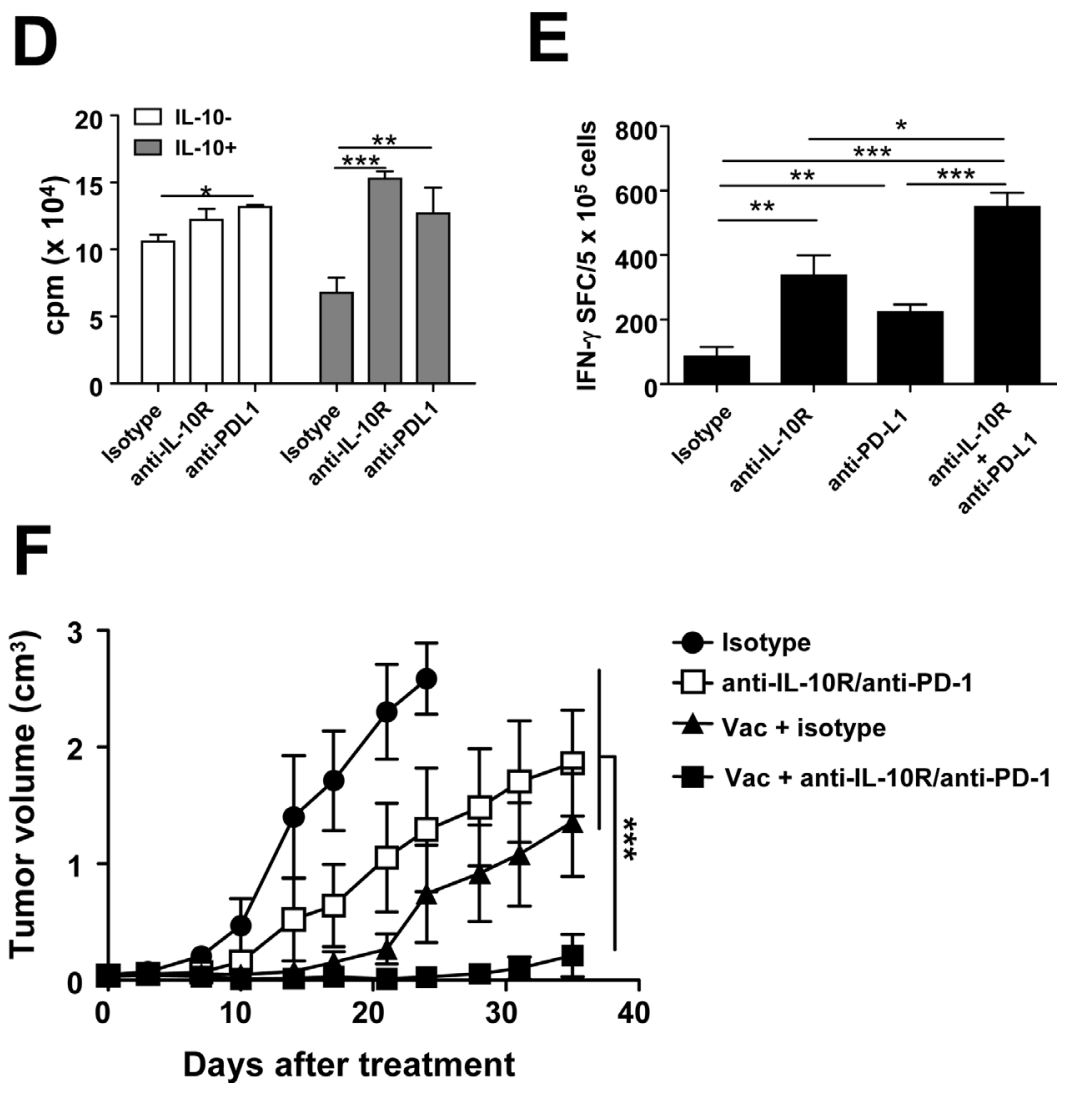

Figure 6: Blockade of vaccination-induced IL-10/PD-L1 in DC potentiates T-cell responses and increases antitumor therapeutic efficacy. (A) Naive or B16-OVA tumor-bearing Vert-X mice $(n=4 /$ group $)$ were vaccinated with OVA+Imiquimod, OVA+poly(I:C) or left untreated. Two days later PD-L1 expression was determined in DC. (B) Vert-X mice ( $n=4 /$ group) were vaccinated with OVA+Imiquimod with or without IL-10 blockade and PD-L1 expression was determined two days later in IL-10- and IL-10 ${ }^{+}$DC. (C) Vert-X mice ( $n=4$ /group) were vaccinated with OVA+Imiquimod with or without PD-L1 blockade and the proportion of IL- $10^{+}$DC was determined two days later. (D) IL-10- and IL-10+ DC obtained from OVA+Imiquimod-vaccinated mice were used to stimulate OT-I CD8 T-cells in the presence of OVA(257-264) plus control or IL-10R- or PD-L1-blocking antibodies. T-cell proliferation was determined three days later. (E) C57BL/6 mice ( $n=4$ /group) were vaccinated with OVA+Imiquimod together with control or IL-10R- or PD-L1blocking antibodies and one week later OVA(257-264)-specific responses were determined by ELISPOT. (F) C57BL/6 mice $(n=7-8 /$ group) bearing $5 \mathrm{~mm}$ B16-OVA tumors were treated with three weekly vaccination cycles with OVA+Imiquimod with or without IL-10R/ PD-1-blocking antibodies and tumor volume was monitored. Results are representative of 2-3 independent experiments. 


\section{DISCUSSION}

Activation of immunity is accompanied by concomitant triggering of self-regulatory mechanisms to avoid excessive responses with harmful effects. However, in cancer, either during tumor progression or as a consequence of therapies, some control mechanisms are over-expressed and preclude correct induction of antitumor responses. Here we have analyzed the role of IL-10, a cytokine with controversial effects on tumor immunity [16], reported as detrimental for T-cell priming during therapeutic vaccination $[23,25]$. We have observed in different tumor models that, although several cell subsets may produce IL-10 upon Imiquimod-based vaccination, APC (namely DC) consistently produce IL-10 at early time-points. Tregs or NK cells may also produce important amounts of IL-10; however, this source does not seem to be relevant, since it occurs in the absence of vaccination or with vaccines where IL-10 inhibition is not beneficial. Previous studies in Imiquimod-vaccinated mice have shown the importance of IL-10. Although the relevant IL-10 source was not identified, Tregs and B-cells were discarded [35], in agreement with our results highlighting DC. Immunomodulatory IL-10 produced by DC at early time points [25] is congruent with the role these cells play at initial stages of T-cell activation, whereas production at later time points (e.g., day 7) is associated with Tr1derived IL-10, as reported in a prolonged Imiquimod-based therapy model [22]. Several issues stress the relevance of IL- $10^{+}$DC. First, there is a phenotypical and functional impairment specifically associated to DC expressing this cytokine. Indeed, IL-10 production is associated not only with a less mature DC phenotype (not observed in other APC subsets), but also with a functional impairment in T-cell priming, shown as a poorer stimulatory capacity and as a direct suppressive capacity. Second, the enhanced antitumor immunity resulting from IL-10 blockade during vaccination is associated with effects at the DC level, both by decreasing the number of IL- $10^{+} \mathrm{DC}$ and by upregulating maturation-associated molecules in these cells. Finally, selective depletion of DC-derived IL-10, but not in other APC, leads to improved in vivo responses and antitumor effect. It is interesting to note that not all adjuvants used have shown the same capacity to in vivo induce IL-10-producing DC. Indeed, whereas these cells were not detected in mice immunized with poly(I:C)based vaccines, they were clearly observed when using Imiquimod, LPS or a multiple adjuvant combination (MAC). We previously reported the capacity of MyD88depending adjuvants (Imiquimod, $\mathrm{CpG}$ oligonucleotides) to induce in vitro IL-10 production by DC, as opposed to those independent on MyD88 (poly(I:C), anti-CD40 agonistic antibodies) [23]. Interestingly, it has been reported that IL-10 produced by DC dampens MyD88dependent, but not MyD88-independent signaling [36], suggesting that signalling through receptors which depend on this pathway may be associated to the inhibitory effect that we observe in DC.

Immunoregulatory $\mathrm{IL}-10^{+} \mathrm{DC}$ have been recently described in murine models of sustained inflammation and immunosuppression like chronic infections, characterized by their poor stimulatory capacity associated with increased expression of negative regulatory factors [37, 38]. However, as opposed to IL-10 $0^{+} \mathrm{DC}$ found in our vaccination setting, those IL-10 $0^{+}$DC expressed higher CD80 and CD86 levels [37]. Vaccine-associated acute inflammation versus chronic inflammation corresponding to those settings might explain these differences. Interestingly, in humans, individuals treated with Imiquimod show an early peak of IL-10 at day 2 [39]. Moreover, human DC grown in an IL-10 rich environment display an immature phenotype together with increased IL-10 and PD-L1 expression [40], resembling our results.

Among immunoregulatory molecules overexpressed in IL- $10^{+}$DC, PD-L1 is of special interest due to its prominent role in immunoregulation and the availability of new clinical treatments targeting this pathway [41, 42]. Although DC activation leads to PD-L1 upregulation [9, 28-30], our results show that not all vaccine adjuvants promote $\mathrm{PD}-\mathrm{L} 1$ expression to the same levels. Thus, whereas poly(I:C) upregulates PD-L1 to some extent, Imiquimod induces the highest PD-L1 levels, more evidently in IL- $10^{+} \mathrm{DC}$, reinforcing the immunoregulatory role of this subset. PD-L1 and IL- 10 have been shown to inhibit anti-tumor responses in different tumors [18-20,43]. Although their expression can be mutually regulated [32-34], in our vaccination setting IL-10 and PD-L1 do not exert reciprocal effects. Prolonged expression of these molecules in established tumors, contrary to the short-time induction we see during vaccination, may explain discrepancies observed in the regulation of their mutual expression, resulting in different pathways that induce and control their presence. Interestingly, this expression confers upon them separate inhibitory mechanisms and their blockade independently rescues antigen-presenting properties of IL- $10^{+} \mathrm{DC}$, suggesting that they could be considered as separate targets in strategies aimed at enhancing T-cell responses by potentiating DC activity. Accordingly, their combined blockade during vaccination induces stronger antitumor responses, resulting in a higher therapeutic efficacy. PD-1/PD-L1 blocking therapies are currently being used with interesting results preferentially in PD-L1 ${ }^{+}$tumors. However, besides tumor cells, infiltrating immune cells may also express inhibitory PD-L1 [43]. Our results add a new element to this setting, suggesting a superior beneficial effect of those combination therapies which include vaccines and these checkpoint inhibitors. It has been recently reported that in melanoma patients, NY-ESO-1-specific CD8 T-cells expressing high PD-1 levels upregulate IL-10R upon antigen recognition, being inhibited thus by these two immunosuppressive pathways [44]. Interestingly, simultaneous blockade of these targets 
promoted expansion and antitumor functions of these cells, resembling our in vivo vaccination results. These data suggest that Imiquimod-based vaccination clinical trials [45] could benefit from simultaneous blockade of IL-10 and PD1/PD-L1.

Finally, the concept of antitumor therapeutic vaccine is currently being expanded from the classical antigen+adjuvant administration to therapies that release tumor antigens associated to immunogenic cell death [46]. Some endogenous alarm molecules induced by conventional therapies (e.g. HMGB1) signal in DC through TLR4 [47], a pathway known to induce IL-10 [27]. Thus, it is tempting to speculate that some DC stimulated through this pathway would resemble and acquire the properties of immunoregulatory DC described in the present work, suggesting that ongoing clinical trials combining immunogenic cell death-inducing agents, such as doxorubicin, with anti-PD-1 antibodies (e.g. NCT02181738, NCT02499367, NCT02622074, NCT02331251; clinicaltrials. gov) might also benefit from IL-10 blockade.

In summary, we have described an IL- $10^{+}$DC subset induced by vaccination, with an immature phenotype and poor stimulatory capacity, associated with inhibitory molecules such as PD-L1. Combination of vaccines with blockade of these or additional immunosuppressive targets expressed by these cells may yield more efficient immunotherapeutic protocols.

\section{MATERIALS AND METHODS}

\section{Antigens}

Peptide OVA(257-264) $>95 \%$ pure (NeoMPS) and immunogens OVA (low endotoxin; Hyglos) and EDAHPVE7 have been previously described [23].

\section{Mice}

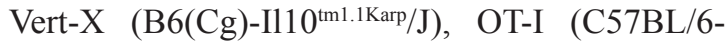
$\mathrm{Tg}($ TcraTcrb) $1100 \mathrm{Mjb} / \mathrm{J})$ and LysMCre (B6.129P2$\left.L y z 2^{\operatorname{tml}(\text { cre) } I f o} / \mathrm{J}\right)$ mice were obtained from Jackson. IL- 10 $0^{\mathrm{f} / \mathrm{fl}}$ (Il10 $\left.{ }^{\text {tm1Roer }}\right)$ and CD11cCre (Tg(Itgax-cre)1-1Reiz) mice were kind gifts from Drs. A. Roers (Institute for Immunology, Dresden; Germany) and D. Sancho (CNIC, Madrid; Spain), respectively. Female C57BL/6 were from Harlan (Barcelona, Spain). They were maintained in pathogen-free conditions and treated according to guidelines of our institution, after study approval by the review committee.

\section{Cell lines}

B16-OVA tumor cells (obtained from Dr. G. Kroemer; Paris, France), E.G7-OVA (from ATCC) and TC-1-P3(A15) cells, (obtained from Dr. T.-C. Wu; Baltimore, USA) were grown as described [23]. Cell stocks were created upon cell line receipt and early passages were used for tumor experiments. They were routinely tested for mycoplasma. Re-authentification of cells was not performed since receipt.

\section{Immunization of mice}

Mice were injected with B16-OVA cells $\left(10^{5}\right.$, intradermally), TC-1-P3(A15) (10 $0^{5}$ subcutaneously) or E.G7-OVA $\left(5 \times 10^{5}\right.$, subcutaneously $)$ and when the tumor diameter reached 4-5 $\mathrm{mm}$, they received intratumoral administration of OVA protein $(0.5 \mathrm{mg} / \mathrm{mouse})$ or EDAHPVE7 immunogen [23] (2 nanomoles) combined with Imiquimod cream (Meda-Aldara ${ }^{\mathrm{TM}}$; topical application; $2.5 \mathrm{mg} / \mathrm{mouse}$ ), poly(I:C) (Amersham; $50 \mu \mathrm{g} / \mathrm{mouse}$; intratumor) or left untreated. Tumor-free mice received similar immunizations by subcutaneous route. At different time-points they were sacrificed and splenocytes, lymph node cells or tumor-infiltrating cells were obtained for characterization. Additionally, they received i.p. injection of anti-IL-10R $(500 \mu \mathrm{g})$, anti-PD-L1 $(200 \mu \mathrm{g})$ or the corresponding isotype control antibodies (all from BioXcell).

\section{Tumor treatment experiments}

Mice bearing 4-5 mm B16-OVA or E.G7-OVA tumors received 3 weekly cycles of OVA (intratumor; $0.5 \mathrm{mg} / \mathrm{mouse}$ ) combined with Imiquimod at day 0 as described [23]. Some groups received anti-IL-10R, antiPD-1 or isotype antibodies as above at days 0,7 and 14. Untreated mice bearing similar tumors were used as positive controls of tumor growth. Tumor volume was calculated using the formula: $\mathrm{V}=\left(\right.$ length $\times$ width $\left.^{2}\right) / 2$. Mice were killed when tumor diameter reached $17 \mathrm{~mm}$.

\section{ELISPOT}

T-cells producing IFN- $\gamma$ were determined by ELISPOT (BD-Biosciences) as described [23]. Splenocytes $\left(5 \times 10^{5} /\right.$ well $)$ were stimulated with peptide OVA(257-264) for $24 \mathrm{~h}$ and the number of spot-forming cells was enumerated with an automated counter.

\section{Flow cytometry}

Lymphoid organs and tumors were obtained after vaccination, treated with collagenase and DNAse for 15 minutes and homogenized. Cells were incubated for 10 min with Fc Block ${ }^{\mathrm{TM}}$ (BD-Biosciences) and stained with specific antibodies. Analysis of cells producing IL10 in Vert-X mice $\left(\mathrm{GFP}^{+}\right.$cells) was performed by using antibodies CD11c-BV570, F4/80-Pacific Blue, CD11bAPC, Ly6C-PE-Cy5 (all from Biolegend) and Ly6GPE-Cy7 (BD-Biosciences), to define DC, monocytes and macrophages. CD3-PE-Cy5 (AbD serotec), NKp46-PE (BD-Biosciences), CD19-APC (BD-Biosciences), CD8 BV421 (Biolegend), CD4-BV570 (Biolegend) and CD25-PE- 
Cy7 (TONBO Biosciences) were used to define lymphocytic subsets (Supplementary Figure S1). For intracellular IL-10 detection in C57BL/6 mice, splenocytes were stimulated 4 $\mathrm{h}$ with PMA/Ionomycin in the presence of GolgiStop and GolgiPlug (BD-Biosciences), surface stained with CD3PE-Cy5, CD8-BV421, CD4-BV570 and CD25-PE-Cy7 antibodies and intracellular stained with anti-IL10-PE (Biolegend). For APC characterization studies, splenocytes were stained in different panels combining CD11c-BV570, F4/80-BV421, CD11b-PE (BD-Biosciences), Ly6C-PE-Cy5, Ly6G-PE-Cy7, CD19-APC-Cy7 (Biolegend), CD80-BV421 (BD-Biosciences), CD54-APC (Biolegend), CD86-PE-Cy5 (Biolegend) or CD86-BV510 (Biolegend), I-A ${ }^{\mathrm{b}}-\mathrm{PE}$ (BDBiosciences) and PD-L1-PE (BD-Biosciences) antibodies. PD-1 expression on CD8 T cells was determined by staining cells obtained from spleen, lymph nodes or tumors with CD8Pacific Blue (AbD Serotec), OVA(257-264)-Tetramer-APC (MBL) and PD-1-FITC (Miltenyi). Samples were acquired in a FACSCantoII flow cytometer (Becton Dickinson) and analyzed using Flowjo software (Tree Star Inc).

\section{Cell purification}

For IL-10 RT-PCR time-course experiments in C57BL/6 mice, animals were vaccinated with OVA+Imiquimod and anti-CD11c-conjugated magnetic beads were used to purify splenic DC, whereas CD4 T-cells were purified by negative selection (Miltenyi; Germany). Splenic IL-10+ and IL-10- DC from Vert-X mice vaccinated with OVA+Imiquimod used for PCR studies, microarrays and antigen presenting assays were purified by using anti-CD11c-conjugated magnetic beads followed by staining with CD11c-APC antibodies (BDBiosciences) and separation with a FACSAria flow cytometer according to their expression of IL-10 (GFP).

\section{Real-time PCR}

Purified DC were resuspended and RNA extracted (Simply RNA Kit; Promega). Real-time PCR was performed as described [26], using primers GGACAACA TACTGCTAACCG and AATCACTCTTCACCTGCTCC (IL-10), AGATGAAGGAGACAGAGGAG and GGAAA AAGCCAACCAAGCAG (IL-12 p40), CTTCCAGAACT CCAGGCGGT and GGTTTGCTCGACGTGGGC (TNF $\alpha)$, CCTTGAAGACCACCACATAG and AGCACCTTTCGAA CATCGTC (IDO) and CGCGTCCACCCGCGAG and CCTG

GTGCCTAGGGCG ( $\beta$-actin). Results were normalized according to b-actin. The amount of each transcript was expressed by the formula: $2^{\Delta \mathrm{Ct}}(\Delta \mathrm{Ct}=\mathrm{Ct}(\beta$-actin $)-\mathrm{Ct}($ gene $))$.

\section{Microarrays}

RNA samples from IL- $10^{+}$and IL-10- DC were labeled, hybridized and scanned according to standard protocols (Affymetrix, Santa Clara, CA, USA). Briefly, $2 \mathrm{ng}$ of RNA were processed using the Affymetrix GeneChip $^{\circledR}$ WT Pico Kit. Hybridization cocktails were hybridized to the GeneChip ${ }^{\circledR}$ Mouse Gene 2.0 ST Arrays, incubated at $45^{\circ} \mathrm{C}$ for 16 hours, washed and stained on an GeneChip $^{\circledR}$ Fluidics 450 workstation (Affymetrix). They were scanned using the Affymetrix GeneChip ${ }^{\circledR}$ Scanner 3000 7G. Data normalization was performed with RMA [48]. After quality assessment using R/Bioconductor [49], a filtering process was carried out to eliminate low expression probe sets. Applying the criterion of an expression value $>4$ in both samples, 30436 probe sets were selected for analysis. Genes were selected as differentially expressed using a fold-change cut off $>1$ and functional enrichment analysis of Gene Ontology categories was performed using the hypergeometric distribution in R. Data are publicly available in GEO database (accession number GSE84980).

\section{Proliferation assays}

In direct antigen presentation assays purified $\mathrm{DC}(6 \times$ $\left.10^{3}\right)$ and OT-I CD8 T-cells $\left(1.8 \times 10^{4}\right)$ were co-cultured $(n=4$ wells/condition) with or without peptide OVA(257264) $(1 \mu \mathrm{g} / \mathrm{ml})$ or OVA protein $(10 \mu \mathrm{g} / \mathrm{ml})$. In some cases, antibodies against IL-10R, PD-L1 or isotype control $(10 \mu \mathrm{g} / \mathrm{ml})$ were also added. Two days later $0.5 \mu \mathrm{Ci}$ of $\mathrm{H}^{3}-$ thymidine were added and cell proliferation was counted after overnight incubation. For suppression assays, $10^{5}$ OT-I total splenocytes were pulsed for $2 \mathrm{~h}$ with a suboptimal dose of OVA(257-264) (1 ng/ml), then peptide was extensively washed, $1.5 \times 10^{4}$ unpulsed IL-10 $0^{+}$or IL-10- DC were added and $\mathrm{T}$ cell proliferation was measured as above.

\section{Statistical analysis}

Tumor growth was fitted to a third order polynomial and compared with the Extra sum-of-squares $\mathrm{F}$ test. Immune responses were analyzed using nonparametric Kruskal-Wallis and Mann-Whitney U tests. $p<0.05$ was taken to represent statistical significance.

\section{ACKNOWLEDGMENTS}

Authors thank Drs. Kroemer and Wu for the kind gift of cell lines, Drs. Roers and Sancho for providing different murine strains, Dr. Rodriguez (CIMA) for his help with LysMcre mice and E. Elizalde for her help with PCR studies. Members of animal facility and Genomics Unit at CIMA are also acknowledged.

\section{CONFLICTS OF INTEREST}

The authors declare no potential conflicts of interest.

\section{GRANT SUPPORT}

This work was supported by Ministerio de Economia y Competitividad/Instituto de Salud Carlos III (grant PI14/00343) to PS. 


\section{REFERENCES}

1. Rabinovich GA, Gabrilovich D, Sotomayor EM. Immunosuppressive strategies that are mediated by tumor cells. Annu Rev Immunol. 2007; 25:267-96.

2. Hargadon KM. Tumor-altered dendritic cell function: implications for anti-tumor immunity. Front Immunol. 2013; 4:192.

3. Dong H, Strome SE, Salomao DR, Tamura H, Hirano F, Flies DB, Roche PC, Lu J, Zhu G, Tamada K, Lennon VA, Celis E, Chen L. Tumor-associated B7-H1 promotes T-cell apoptosis: a potential mechanism of immune evasion. Nat Med. 2002; 8:793-800.

4. Imai N, Ikeda H, Tawara I, Shiku H. Tumor progression inhibits the induction of multifunctionality in adoptively transferred tumor-specific CD8+ T cells. Eur J Immunol. 2009; 39:241-53.

5. Shin DS, Ribas A. The evolution of checkpoint blockade as a cancer therapy: what's here, what's next? Curr Opin Immunol. 2015; 33:23-35.

6. Postow MA, Callahan MK, Wolchok JD. Immune Checkpoint Blockade in Cancer Therapy. J Clin Oncol. 2015; 33:1974-82.

7. Twyman-Saint Victor C, Rech AJ, Maity A, Rengan R, Pauken KE, Stelekati E, Benci JL, Xu B, Dada H, Odorizzi PM, Herati RS, Mansfield KD, Patsch D, et al. Radiation and dual checkpoint blockade activate nonredundant immune mechanisms in cancer. Nature. 2015; 520:373-7.

8. Wobser M, Voigt H, Houben R, Eggert AO, Freiwald M, Kaemmerer U, Kaempgen E, Schrama D, Becker JC. Dendritic cell based antitumor vaccination: impact of functional indoleamine 2,3-dioxygenase expression. Cancer Immunol Immunother. 2007; 56:1017-24.

9. Pulko V, Liu X, Krco CJ, Harris KJ, Frigola X, Kwon ED, Dong H. TLR3-stimulated dendritic cells up-regulate B7-H1 expression and influence the magnitude of CD8 $\mathrm{T}$ cell responses to tumor vaccination. J Immunol. 2009; 183:3634-41.

10. Cho HI, Lee YR, Celis E. Interferon gamma limits the effectiveness of melanoma peptide vaccines. Blood. 2011; 117:135-44.

11. Dang Y, Wagner WM, Gad E, Rastetter L, Berger CM, Holt GE, Disis ML. Dendritic cell-activating vaccine adjuvants differ in the ability to elicit antitumor immunity due to an adjuvant-specific induction of immunosuppressive cells. Clin Cancer Res. 2012; 18:3122-31.

12. Sui Y, Hogg A, Wang Y, Frey B, Yu H, Xia Z, Venzon D, McKinnon K, Smedley J, Gathuka M, Klinman D, Keele BF, Langermann S, et al. Vaccine-induced myeloid cell population dampens protective immunity to SIV. J Clin Invest. 2014; 124:2538-49.

13. de Vries JE. Immunosuppressive and anti-inflammatory properties of interleukin 10. Ann Med. 1995; 27:537-41.
14. Saraiva M, O'Garra A. The regulation of IL-10 production by immune cells. Nat Rev Immunol. 2010; 10:170-81.

15. Groux H, Bigler M, de Vries JE, Roncarolo MG. Inhibitory and stimulatory effects of IL-10 on human CD8+ T cells. J Immunol. 1998; 160:3188-93.

16. Mocellin S, Panelli MC, Wang E, Nagorsen D, Marincola FM. The dual role of IL-10. Trends Immunol. 2003; 24:36-43.

17. Emmerich J, Mumm JB, Chan IH, LaFace D, Truong H, McClanahan T, Gorman DM, Oft M. IL-10 directly activates and expands tumor-resident $\mathrm{CD} 8(+) \mathrm{T}$ cells without de novo infiltration from secondary lymphoid organs. Cancer Res. 2012; 72:3570-81.

18. Fujieda S, Lee K, Sunaga H, Tsuzuki H, Ikawa H, Fan GK, Imanaka M, Takenaka H, Saito H. Staining of interleukin-10 predicts clinical outcome in patients with nasopharyngeal carcinoma. Cancer. 1999; 85:1439-45.

19. Chau GY, Wu CW, Lui WY, Chang TJ, Kao HL, Wu LH, King KL, Loong CC, Hsia CY, Chi CW. Serum interleukin-10 but not interleukin-6 is related to clinical outcome in patients with resectable hepatocellular carcinoma. Ann Surg. 2000; 231:552-8.

20. Hamidullah, Changkija B, Konwar R. Role of interleukin-10 in breast cancer. Breast Cancer Res Treat. 2012; 133:11-21.

21. O’Garra A, Barrat FJ, Castro AG, Vicari A, Hawrylowicz C. Strategies for use of IL-10 or its antagonists in human disease. Immunol Rev. 2008; 223:114-31.

22. Lu H, Wagner WM, Gad E, Yang Y, Duan H, Amon LM, Van Denend N, Larson ER, Chang A, Tufvesson H, Disis ML. Treatment failure of a TLR-7 agonist occurs due to selfregulation of acute inflammation and can be overcome by IL-10 blockade. J Immunol. 2010; 184:5360-7.

23. Llopiz D, Aranda F, Díaz-Valdés N, Ruiz M, Infante S, Belsúe V, Lasarte JJ, Sarobe P. Vaccine-induced but not tumor-derived Interleukin-10 dictates the efficacy of Interleukin-10 blockade in therapeutic vaccination. Oncoimmunology. 2016; 5:e1075113.

24. Madan R, Demircik F, Surianarayanan S, Allen JL, Divanovic S, Trompette A, Yogev N, Gu Y, Khodoun M, Hildeman D, Boespflug N, Fogolin MB, Grobe L, et al. Nonredundant roles for B cell-derived IL-10 in immune counter-regulation. J Immunol. 2009; 183:2312-20.

25. Fu C, Liang $X$, Cui W, Ober-Blobaum JL, Vazzana J, Shrikant PA, Lee KP, Clausen BE, Mellman I, Jiang A. betaCatenin in dendritic cells exerts opposite functions in crosspriming and maintenance of CD8 $+\mathrm{T}$ cells through regulation of IL-10. Proc Natl Acad Sci USA. 2015; 112:2823-8.

26. Aranda F, Llopiz D, Diaz-Valdes N, Riezu-Boj JI, Bezunartea J, Ruiz M, Martinez M, Durantez M, Mansilla C, Prieto J, Lasarte JJ, Borras-Cuesta F, Sarobe P. Adjuvant combination and antigen targeting as a strategy to induce polyfunctional and high-avidity T-cell responses against poorly immunogenic tumors. Cancer Res. 2011; 71:3214-24. 
27. Castro AG, Neighbors M, Hurst SD, Zonin F, Silva RA, Murphy E, Liu YJ, O'Garra A. Anti-interleukin 10 receptor monoclonal antibody is an adjuvant for $\mathrm{T}$ helper cell type 1 responses to soluble antigen only in the presence of lipopolysaccharide. J Exp Med. 2000; 192:1529-34.

28. Meier A, Bagchi A, Sidhu HK, Alter G, Suscovich TJ, Kavanagh DG, Streeck H, Brockman MA, LeGall S, Hellman J, Altfeld M. Upregulation of PD-L1 on monocytes and dendritic cells by HIV-1 derived TLR ligands. Aids. 2008; 22:655-8.

29. Groschel S, Piggott KD, Vaglio A, Ma-Krupa W, Singh K, Goronzy JJ, Weyand CM. TLR-mediated induction of negative regulatory ligands on dendritic cells. J Mol Med (Berl). 2008; 86:443-55.

30. Wolfle SJ, Strebovsky J, Bartz H, Sahr A, Arnold C, Kaiser C, Dalpke AH, Heeg K. PD-L1 expression on tolerogenic APCs is controlled by STAT-3. Eur J Immunol. 2011; 41:413-24.

31. Chen L, Han X. Anti-PD-1/PD-L1 therapy of human cancer: past, present, and future. J Clin Invest. 2015; 125:3384-91.

32. Wu K, Kryczek I, Chen L, Zou W, Welling TH. Kupffer cell suppression of CD8+ T cells in human hepatocellular carcinoma is mediated by B7-H1/programmed death-1 interactions. Cancer Res. 2009; 69:8067-75.

33. Bloch O, Crane CA, Kaur R, Safaee M, Rutkowski MJ, Parsa AT. Gliomas promote immunosuppression through induction of B7-H1 expression in tumor-associated macrophages. Clin Cancer Res. 2013; 19:3165-75.

34. Maine CJ, Aziz NH, Chatterjee J, Hayford C, Brewig N, Whilding L, George AJ, Ghaem-Maghami S. Programmed death ligand-1 over-expression correlates with malignancy and contributes to immune regulation in ovarian cancer. Cancer Immunol Immunother. 2014; 63:215-24.

35. Stein P, Weber M, Prufer S, Schmid B, Schmitt E, Probst HC, Waisman A, Langguth P, Schild H, Radsak MP. Regulatory $\mathrm{T}$ cells and IL-10 independently counterregulate cytotoxic $\mathrm{T}$ lymphocyte responses induced by transcutaneous immunization. PLoS One. 2011; 6:e27911.

36. Chang J, Kunkel SL, Chang CH. Negative regulation of MyD88-dependent signaling by IL-10 in dendritic cells. Proc Natl Acad Sci USA. 2009; 106:18327-32.

37. Wilson EB, Kidani Y, Elsaesser H, Barnard J, Raff L, Karp CL, Bensinger S, Brooks DG. Emergence of distinct multiarmed immunoregulatory antigen-presenting cells during persistent viral infection. Cell Host Microbe. 2012; 11:481-91.

38. Cunningham CR, Champhekar A, Tullius MV, Dillon BJ, Zhen A, de la Fuente JR, Herskovitz J, Elsaesser H, Snell LM, Wilson EB, de la Torre JC, Kitchen SG, Horwitz MA, et al. Type I and Type II Interferon Coordinately Regulate Suppressive Dendritic Cell Fate and Function during Viral Persistence. PLoS Pathog. 2016; 12:e1005356.
39. Vinter H, Iversen L, Steiniche T, Kragballe K, Johansen C. Aldara(R)-induced skin inflammation: studies of patients with psoriasis. Br J Dermatol. 2015; 172:345-53.

40. Lindenberg JJ, van de Ven R, Lougheed SM, Zomer A, Santegoets SJ, Griffioen AW, Hooijberg E, van den Eertwegh AJ, Thijssen VL, Scheper RJ, Oosterhoff D, de Gruijl TD. Functional characterization of a STAT3dependent dendritic cell-derived CD14 cell population arising upon IL-10-driven maturation. Oncoimmunology. 2013; 2:e23837.

41. Topalian SL, Hodi FS, Brahmer JR, Gettinger SN, Smith DC, McDermott DF, Powderly JD, Carvajal RD, Sosman JA, Atkins MB, Leming PD, Spigel DR, Antonia SJ, et al. Safety, activity, and immune correlates of anti-PD-1 antibody in cancer. N Engl J Med. 2012; 366:2443-54.

42. Brahmer JR, Tykodi SS, Chow LQ, Hwu WJ, Topalian SL, Hwu P, Drake CG, Camacho LH, Kauh J, Odunsi K, Pitot HC, Hamid O, Bhatia S, et al. Safety and activity of anti-PD-L1 antibody in patients with advanced cancer. N Engl J Med. 2012; 366:2455-65.

43. Herbst RS, Soria JC, Kowanetz M, Fine GD, Hamid O, Gordon MS, Sosman JA, McDermott DF, Powderly JD, Gettinger SN, Kohrt HE, Horn L, Lawrence DP, et al. Predictive correlates of response to the anti-PD-L1 antibody MPDL3280A in cancer patients. Nature. 2014; 515:563-7.

44. Sun Z, Fourcade J, Pagliano O, Chauvin JM, Sander C, Kirkwood JM, Zarour HM. IL10 and PD-1 Cooperate to Limit the Activity of Tumor-Specific CD8+ T Cells. Cancer Res. 2015; 75:1635-44.

45. Adams S, O’Neill DW, Nonaka D, Hardin E, Chiriboga L, Siu K, Cruz CM, Angiulli A, Angiulli F, Ritter E, Holman RM, Shapiro RL, Berman RS, et al. Immunization of malignant melanoma patients with full-length NY-ESO-1 protein using TLR7 agonist imiquimod as vaccine adjuvant. J Immunol. 2008; 181:776-84.

46. Mellman I, Hubbard-Lucey VM, Tontonoz MJ, Kalos MD, Chen DS, Allison JP, Drake CG, Levitsky H, Lonberg N, van der Burg SH, Fearon DT, Wherry EJ, Lowy I, et al. DeRisking Immunotherapy: Report of a Consensus Workshop of the Cancer Immunotherapy Consortium of the Cancer Research Institute. Cancer Immunol Res. 2016; 4:279-88.

47. Apetoh L, Ghiringhelli F, Tesniere A, Obeid M, Ortiz C, Criollo A, Mignot G, Maiuri MC, Ullrich E, Saulnier P, Yang H, Amigorena S, Ryffel B, et al. Toll-like receptor 4-dependent contribution of the immune system to anticancer chemotherapy and radiotherapy. Nat Med. 2007; 13:1050-9.

48. Irizarry RA, Bolstad BM, Collin F, Cope LM, Hobbs B, Speed TP. Summaries of Affymetrix GeneChip probe level data. Nucleic Acids Res. 2003; 31:e15.

49. Gentleman R, Carey V, Dudoit S, Irizarry R, Huber W, (ed.). Bioinformatics and computational biology solutions using $\mathrm{R}$ and Bioconductor. (New York, NY: Springer). 2005. 